\title{
The Effects of Interior Design Parameters on the Design Quality of Nurse Stations ${ }^{1}$
}

\author{
By Cigdem Cetin ${ }^{*}$ \\ Zeynep Tuna Ultav ${ }^{+}$ \\ Gulnur Ballice
}

This paper focuses on the significance of design quality in working areas of nurses in healthcare interiors. Although nurses are healthcare staff that are in close contact with patients and have busy schedules during their working hours, their satisfaction and perceptions are not considered thoroughly in healthcare interiors. Several reasons can be affecting this issue; but lack of awareness and lack of supply-demand are the most preliminary and significant problems in this study. Therefore, the study aims to expand awareness on the importance of design quality in nurse stations regarding the role of interior design parameters. Understanding the role of design parameters affecting nurses' perceptions of working areas are crucial parameters for positive evaluations of healthcare interiors. In this context, plan layout, color, material, furniture and lighting as interior design parameters were analyzed according to the physical and psychological needs of nurses in this study. Methodology of the study includes face-to-face questionnaires, which were conducted with 127 nurses from selected four hospitals located in İmir. Questionnaires consisted of five parts: pre-questionnaire, plan and furniture layout, color, light and material. The data were analyzed through SPSS software. In addition to the questionnaires, two nurses from each of the four hospitals were interviewed. The overall analysis was reevaluated by literature review as well as the results from observations. In conclusion, the physical and psychological needs of nurses in their working area were revealed.

\section{Introduction}

This paper focuses on the significance of design quality in working areas of nurses in healthcare interiors. It analyzes the parameters of interior design of nurse stations for increasing the quality of these spaces according to approaches commonly stated by EBD and UCD. Understanding the role of design parameters affecting nurses' perceptions of working areas are crucial parameters for positive evaluations of healthcare interiors. In this context, plan layout, color, material, furniture and lighting as interior design parameters were analyzed according to the physical and psychological needs of nurses in this study. Methodology of the study includes face-to-face questionnaires, which were conducted with 127 nurses from four selected hospitals (Urla Public Hospital, Çeşme Public Hospital, Tire Public Hospital, Tepecik Training

\footnotetext{
*Assistant Professor, Yasar University, Turkey.

${ }^{\dagger}$ Associate Professor, Yasar University, Turkey.

Associate Professor, Yasar University, Turkey.

${ }^{1}$ This study is supported within the scope of BAP048 Research Project which is accepted by Yaşar University Project Evaluation Commission.
} 
Research Hospital Bornova Additional Service Building) located in İzmir. Questionnaires consisted of five parts, regarding a pre-questionnaire, plan layout, furniture, color, lighting and material. The data were analyzed through SPSS software. In addition to the questionnaires, two nurses from each of the four hospitals were interviewed.

Due to intense work pressure and long work hours, nursing is considered one of the most stressful professions. The difficulty of day and night adaptability, as well as the necessity of working in multiple areas during work hours, also play an increasing role in their stress and hence affect their quality of life. Although nurses are healthcare staff that are in close contact with patients and have busy schedules during their work hours, unfortunately their satisfaction and perceptions are not considered thoroughly in healthcare interiors. Several reasons could be affecting this issue:

- Inadequacy of education and awareness of the relevant management units

- Limited budget for staff and their spatial requirements

- Prioritizing spaces belonging to patients

- Limitedness of spaces allocated for staff within the total area in healthcare facilities

- The spaces of healthcare staff are not defined precisely by the standards in regulations

- The design decisions (visual, audial, thermal, ergonomic etc.) affecting the quality of interior in staff spaces are secondary to architectural planning

Besides these reasons, lack of awareness and lack of supply-demand on this topic are the most preliminary and significant problems defined for this study. There are many researches questioning the "quality in healthcare facilities" in terms of physical, mechanical or psychological aspects. A great amount of them are focused on objective issues, such as thermal comfort, energy use, control of acoustics, ventilation systems, plan configuration, façade solutions etc. Some of the studies analyze spaces with a subjective approach (physical and psychological needs of human), but usually just from the patient's point of view. Therefore, this study aims to investigate working areas of nurses with both objective and subjective perspectives in order to enhance the quality of interior design and thereby the perceptions of nurses that use these spaces.

Perception of nurses in their working areas depends on social and spatial parameters. Besides their relationships with other staff, patients and their families or visitors, social relations they encounter in their life also affect their perception. Harris et al. highlights three dimensions that have effects on health and well-being: architectural features (e.g., spatial layout, room size), ambient features (e.g., lighting, odors), and interior design features (e.g., color, artwork, indoor plants). In this respect, plan and furniture layout, lighting, color and materials were analyzed according to physical and psychological needs of nurses in this study. 


\section{Literature Review}

Interior design of healthcare facilities has generally focused more on physical issues, such as providing adequate spaces for appropriate functions or using sufficient ventilation for surgery rooms, etc. However, in recent years, it has started to be understood that to regard only physical needs is not sufficient for ensuring satisfaction from these facilities. As Ruga (1989) states, design should accomplish more than creating functional efficiency, marketing or cost and codes. ${ }^{2}$ Furthermore, the other crucial aim of design is to create "psychologically supportive" spaces. ${ }^{3}$

\section{Evidence Based Design (EBD)}

The effects of design in healing environments are considered to be more important and it leads to increase a need of evidence to use as a guide on designing healthcare interiors and this contributed to the emergence of a new term "evidence based design" (EBD). Evidence-based design is the process of making fundamental decisions about the built environment based on reliable research data in order to achieve the most successful and possible outcomes. ${ }^{4}$ This theory supports Ulrich's "supportive theory" and adds evidence-based criteria for having positive impacts on patient outcome, as well as improving hospital staff functions further than aesthetic and psychological aspects of interior design for healthcare facilities. ${ }^{5}$ In this theory, the information produced in the process of EBD, is based on verified results of research and analysis of POE (Post Efficiency Evaluation). ${ }^{6}$ EBD focuses on a wide variety of research topics in healthcare design such as safety, number of patients in the rooms, ventilation, acoustics, light, the impact of the built environment on therapeutic outcomes, stress reduction, friendly workplace, staff efficiency and so on. ${ }^{7}$ EBD also proposes some measures for improving staff outcomes with the help of interior design parameters. These are: decreasing staff injuries, decreasing staff stress, increasing staff effectiveness, and increasing staff satisfaction. ${ }^{8}$

2. W. Ruga, Designing for the six senses, Journal of Health Care Interior Design 1 (1989): 29-34.

3. R. S. Ulrich, "Effects of interior design on wellness: Theory and recent scientific research," Journal of Health Care Interior Design 3 (1991): 97-109.

4. Center for Health Design, An Introduction to Evidence Based Design for Healthcare Facilities (Concord, CA: The Center for Health Design, 2008); C. McCullough, EvidenceBased Design for Healthcare Facilities (USA: Sigma Theta Tau, 2009).

5. McCullough, Evidence-Based Design for Healthcare Facilities, 2009.

6. B. L. Sadler, J. Du Bose and C. Zimring, "The business case for building better hospitals through evidence-based design," Health Environments Research and Design 1, no. 3 (2008): 22-39.

7. B. Jakub, "Evidence based design for contemporary healthcare facilities," Space and Form 29 (2014).

8. S. Tanriöver, "The healing \& supportive role of design in healthcare environments: Evidence Based Healthcare Design," presentation within the course of "INAR 371 perception 


\section{Decreasing Staff Stress}

The stress factors on healthcare staff are sourced from operational factors and environmental/spatial factors. Research shows that lack of control of the environment and existence problems in space stemming from the building may cause problems like blockage and social isolation for staff. In accordance, it leads to problems in jobs, social issues, and negative outcomes regarding the mental health of individuals. ${ }^{9}$ Operationally speaking, healthcare staff, especially nurses, have to work with a high level of stress and this can result in them leaving work. Especially in ICU (Intensive Care Unit), nurses are more stressed compared with others, leading to a high level of anxiety. Therefore, they are more susceptible to making medical errors and performing poorly. Spatially speaking, noise, light, multi-bed patient rooms and crowding, cause stress at work. Besides controlling these factors for physical needs, controlling these factors for psychological needs such as privacy, a sense of belonging and borders is important as well. ${ }^{10}$

\section{Increasing Staff Effectives}

The quality in healthcare interiors gets important in order to improve staff's job satisfaction and dependently their performance. Environmental factors affecting staff performance are; unit configuration (Patient areas/nurse stations/pharmacy), layout of spaces (radial, rectangular, single corridor, double corridor types; radial type shorten the way of accessing to patient rooms from nurse station, decentralized of nurse station and co-location of similar activities have more advantages for saving time), and noise level. ${ }^{11}$

\section{Increasing Staff Satisfaction}

Despite their long working hours and stressful work schedule, it is possible to increase job satisfaction of staff with spatial parameters. Providing natural light to their work environment is especially important for their satisfaction, as luminous environments improve moods and reduce stress. ${ }^{12}$ According to research by Tavakkoli et al. (2015), nurses who worked in a simulated garden or saw it from a window have more job satisfaction compared with others working in an environment without any design. ${ }^{13}$

in interiors" seminar entitled Healing Role of Space on the Design of Healthcare Buildings (Yaşar University, 2016).

9. R. Gifford, "Environmental psychology and sustainable development: Expansion, maturation, and challenges," Journal of Social Issues 63 (2007): 199-212.

10. Tanriöver, "The healing \& supportive role of design in healthcare environments: Evidence Based Healthcare Design,” 2016.

11. Ibid.

12. Ibid.

13. S. Tavakkoli, M. M. Asaadi, A. H. Pakpour and M. Hajiaghababaei, "Environmental psychology effects on mental health job satisfaction and personal well being of nurses," Iranian Journal of Psychiatry 10, no. 3 (2015): 158-164. 


\section{User Centered Design}

As EBD states, in addition to scientific researches, analysis of the evaluation of users are a significant part of holistic design approach. In this context, the other term that the study references is "user centered design (UCD)". ${ }^{14}$ It is obvious to say that healthcare interior design has to be in close contact with users. Therefore, the design should be planned according to users' physical and psychological characteristics with the simplest solutions. Similarly, the American Society of Interior Design (ASID) describes the essence of interior design not just as functional, but also as an enhancement to the quality of life and culture of the users. ${ }^{15}$

Nurses are the caregivers that must move among the spaces during their working time. Furthermore, all their activities have to be completed in a minimum time sequence. Thus, nursing in acute care settings demands an important level of multitasking work capability and intense attention with cognitive workload. ${ }^{16}$ For this purpose, patient care workflows must accordingly reduce interruptions, provide an environment that enables performing a diverse range of tasks, and minimizes errors or omissions. ${ }^{17}$ There are many parameters affecting work conditions. Besides the social inputs, operational factors and individual profile of the nurses, the design quality of work environment should serve the best conditions to them during their work hours. According to $\mathrm{Wu}$ (2000), many errors caused by routines, systems and settings, give harm to patients and also affect caregivers and cause stress and burnout. ${ }^{18}$ The other advantage of designing high quality work environments for nurses is revealed by a survey that discusses decisions of nurses to work in hospitals according to many criteria, including the workplace parameters. ${ }^{19}$ In sum, analyzing and focusing on the perceptions of quality and satisfaction of nurses can increase the academic and professional value of hospitals. ${ }^{20}$

14. The term was firstly used in 1980 at University of California San Diego for the field of computer. The aim of the term is to get interaction with user and computer system with a basic process that decreases the time on training for operating this system (Haliloğlu Kahraman, 2010).

15. R. S. Zadeh, M. M. Shepley and L. T. Waggener, "Rethinking efficiency in acute care nursing units: analyzing nursing unit layouts for improved spatial," HERD-Health Environments Research \& Design Journal 6, no. 1 (2012): 39-65.

16. P. Potter, L. Wolf, S. Boxerman, D. Grayson, J. Sledge, C. Dunagan and B. Evanoff, "Understanding the cognitive work of nursing in the acute care environment," Journal of Nursing Administration 35, no. 7-8 (2005): 327-335.

17. Zadeh, Shepley and Waggener, "Rethinking efficiency in acute care nursing units: analyzing nursing unit layouts for improved spatial," 2012.

18. A. W. Wu, "Medical error: The second victim," British Medical Journal 320 (2000): 726-727.

19. C. Andrade, M. L. Lima, F. Fornara and M. Bonaiuto, 'Users' Views of Hospital Environmental Quality: Validation of the Perceived Hospital Environment Quality Indicators (PHEQIs)," Journal of Environmental Psychology 32, no. 2 (2012): 97-111.

20. C. Andrade and A. S. Devlin, "Stress reduction in the hospital room: Applying Ulrich's theory of supportive design," Journal of Environmental Psychology 41 (2014): 125134. 
The Parameters of Interior Design of Nurse Stations

\section{Plan and Furniture Layout}

Nurse stations are generally located in the centralized point of the floors in healthcare interiors and the other facilities surround it. Therefore, nurses spend most of their time walking up and down the corridor. Accordingly, increases in fatigue and decreases in time for observation and direct care are seen. ${ }^{21}$ Relevantly, a study shows that almost one third of nurses' time was spent walking from one station to another. Therefore, more efficient plan configurations of nurse stations could save time for patient care. ${ }^{22}$

The layout of furniture in an interior is a fundamental sub-topic in plan layout. It affects both the physical function of the space and the psychology of the user. Nurses' work stations require appropriate and sufficient surfaces in order to afford a wide variety of functions, such as contacting patients, family and other staff, sitting and entering data to computers, using printers, preparing medicine, etc. With this purpose, the intensity, orientation, size and shape of the furniture should allow these activities. The layout of the furniture also affects social contact. Furniture should allow immobility and give an appropriate and controlled distance for dialogue, as well as contribute to socialization without any disturbance. ${ }^{23}$ In addition, furnishing in these stations should be flexible for rapid changes in order to adapt with each care delivery model. ${ }^{24}$

Color

Using color in a proper way in the interior design of healthcare facilities has an underestimated positive effect on users. The Center for Health Care Design stated that color is an important environmental parameter in the design of hospitals that needs to be further studied. Studies show that color and light relation can affect concentration, alertness, aggression, stress, and even dyslexia. ${ }^{25}$ According to Sharpe (1974), cool colors such as blue or green, used with low illumination level, neutralize the negative effects of noise and support concentration on difficult tasks. ${ }^{26}$

21. R. Ulrich, C. Zimring, A. Joseph, X. Quan and R. Choudhary, The role of the physical environment in the hospital of the 21st century: a once-in-a lifetime opportunity (Concord, CA: Center for Health Design, 2004).

22. Ibid; O. Dikmen, Children's Hospital Schools as Social Environments and Their Effects on Healing and Well-Being: Case Study in Izmir Behçet Uz Children's Hospital School (Master Thesis. Izmir University of Economics, 2012).

23. G. W. Evans and J. M. McCoy, "When buildings don't work: The role of architecture in human health," Journal of Environmental Psychology 18, no. 1 (1998): 85-94.

24. A. Morelli, Implications of Nursing Station Design on Nurses' Psychosocial Health and Work Behavior (Master Thesis. Environmental Psychology D, 2007).

25. A. Demarco and N. Clarke, "An interview with Alison Demarco and Nichol Clarke: Light and colour therapy explained," Complementary Therapies in Nursing and Midwifery 7 (2001): 95-103.

26. D. T. Sharpe, The Psychology of Color and Design (Chicago: Nelson-Hall Co, 1974). 
While deciding color schema for a space in healthcare interiors, criteria such as function of space, types of tasks, the level of visual acuity and contrast desired should be considered. Especially in nurse stations, contrast with figure and ground should be considered in high level to be perceived by all groups of users. ${ }^{27}$

The other aim of color in nurse stations is to give pleasure to the nurses themselves. For instance, exposure to cool colors for long hours can irritate them. ${ }^{28}$ However, cool colors increase concentration in space while warm ones decrease concentration. In addition, the passing of time in a space colored by cool colors is perceived more than time in a space colored by warm colors. ${ }^{29}$ Colors also affect the perception of dimensions of space. Warm and dark colors on the ceiling and walls make these surfaces seem closer to the user. Also, floors are perceived as safer with warm and dark colors, but clean and broad with cool and light colors.

\section{Light}

The main aim of well-designed lighting is to create an environment that ensures good visibility and luminous environment that does not permit visual disorders. However, for architectural lighting, visual comfort and satisfaction are also important in physical and psychological aspects. ${ }^{30}$

Especially in healthcare environments, lighting has an important value in terms of navigation, wayfinding, aesthetic, user friendly, safety, coding, promoting a sense of well-being and even on recovery rates. ${ }^{31}$ Likewise, natural and artificial light have significant effects on human health and comfort. These may be the perception of feelings like the influence of brain on human physiology and biology, blood circulation and pressure, deteriorations on body resistance and balance, as in human psychology; happiness, spaciousness and relaxation according to soul and emotional mood. ${ }^{32}$ For these points, access to natural light is preferable over artificial light in healthcare interiors. According to research done on the importance of natural light exposure, a

27. A. S. Karakurt, Critical Analysis and Evaluation of Hospital Main Entrances According to Design and Performance Criteria in the Case of Turkey (Master Thesis. Middle East Technical University, 2003).

28. Ibid.

29. P. Barış1k, The Relationship between Behavioral and Sensory Comfort Parameters and Spatial Organisation in Hospital Polyclinic Spaces (Master Thesis. Beykent University, 2013).

30. Ibid; S. F. İğdir, Evaluation of Design Studios in Terms of Environmental Comfort Conditions (Master Thesis. Bilkent University, 1998).

31. H. Dalke, J. Little, E. Niemann, N. Camgoz, G. Steadman, S. Hill and L. Stott, "Colour and lighting in hospital design," Optics and Laser Technology 38, no. 4 (2006): 343365; C. Çetinkaya, A. Cılasun and B. Hancı Geçit, "Evaluation of indoor environmental control and psychology in healthcare: a case study on inpatient rooms in hospitals," in Proceedings of the SBE Symposium (Istanbul, 2016), 474-482.

32. N. C. Ruck, Building Design and Human Performance (New York: Van Nostrand Reinhold, 1989). 
lack of windows can arouse anxiety and may even cause psychosis. ${ }^{33}$ Thus, natural light in healthcare interiors should be provided as much as possible.

Particularly in nurse stations, visibility, accessibility, and the affordance of tasks with physical and psychological comfort become more important both in day and night. For appropriate lighting, quantity, quality, luminous levels and surface features in the environment should all be regarded. ${ }^{34}$ The lighting scheme in nurse working stations should be planned with lighting elements in low glare and task lighting illuminance for reducing reflection from display screens. ${ }^{35}$ Especially at night, the luminance level in these spaces and corridors should be dimmed according to the luminance levels at the nursing area in order to allow for visual adaptation and way finding. ${ }^{36}$

It is also known that if lighting sources are small or if a bundle of lights is parallel, the light given off will be more contrasting and shadows will be more dramatic and dark. On the contrary, if a lighting source is larger and its given light is wider, it will be less contrasting and shadows will be more transparent. ${ }^{37}$ Thus, wider light sources should be used to avoid dramatic shadows. In summary, for well-designed lighting in nurse stations, direct or indirect glare as well as luminaire and visual noise must be prevented. In addition, homogeneity of dark and light adaptation, dimmed control of lighting, legibility and visibility of signs and use of high color rendering indexes in lighting sources, as well as a full spectrum artificial light must be provided. ${ }^{38}$

\section{Material}

Materials create different effects on humans with their physical, mechanical and formal properties, for example surface qualities. For healthcare interiors, physical properties such as safety, capacity for easy cleaning, maintenance, and appropriateness for different users can be listed as the main parameters. Materials used in a nurse station can be classified by three surfaces. The surface most used and open to impact is the floor. Thus, floor material should be well-considered in terms of durability and maintenance. Hard surface flooring includes resilient properties - like sheet vinyl (compact homogeny or heterogenic), compact linoleum or other sheet materials, terrazzo, vinyl composition tile (VCT), porcelain pavers, ceramic tile, and natural stone -

33. Ulrich, "Effects of interior design on wellness: Theory and recent scientific research," 1991.

34. Barışı, The Relationship between Behavioral and Sensory Comfort Parameters and Spatial Organisation in Hospital Polyclinic Spaces, 2013.

35. O. Sylvania, Lighting Options by Space or Area: Nursing Stations, 2012.

36. Erdemli, Esen, Hilal, Jakshybekov, Öktem, Özmen, Şengül, Turgay, Tünger and Zeka, Design Guidelines for Nonclinical Areas in Hospitals: Case of Güven Hospital (Graduate Student Work. Bilkent University, 2013).

37. S. Göler, Style, Color, Material, Texture and Light Effects on the Location of Perception (Master Thesis. Mimar Sinan Fine Art University, 2009).

38. J. Malkin, Hospital Interior Architecture: Creating Healing Environment for Special Patient Populations (New York: Van Nostrand Reinhold, 1992); Erdemli, Esen, Hilal, Jakshybekov, Öktem, Özmen, Şengül, Turgay, Tünger and Zeka, Design Guidelines for Nonclinical Areas in Hospitals: Case of Güven Hospital, 2013. 
and thus is often appropriate for areas like emergency care, nurse stations, corridors, exam rooms, and inpatient rooms where wet conditions can occur and infection control is vital. ${ }^{39}$

\section{Methodology}

The methodology of the study included face-to-face questionnaires, which were conducted with 127 nurses from the selected four hospitals (see Figure 1 and Figure 2) located in İzmir. Questionnaires consisted of six parts, called pre-questionnaire, plan layout, furniture, color, lighting and material and the data were analyzed through SPSS software. In addition to the questionnaires, two nurses from each of the four hospitals were interviewed. The overall analysis was re-evaluated by a literature review as well as the results from observations.

Figure 1. The Selected Four Hospitals, Exterior View (a: Urla State Hospital; b: Çeşme State Hospital; c: Tire State Hospital; d: Tepecik Training Research Hospital Bornova Additional Service Building)
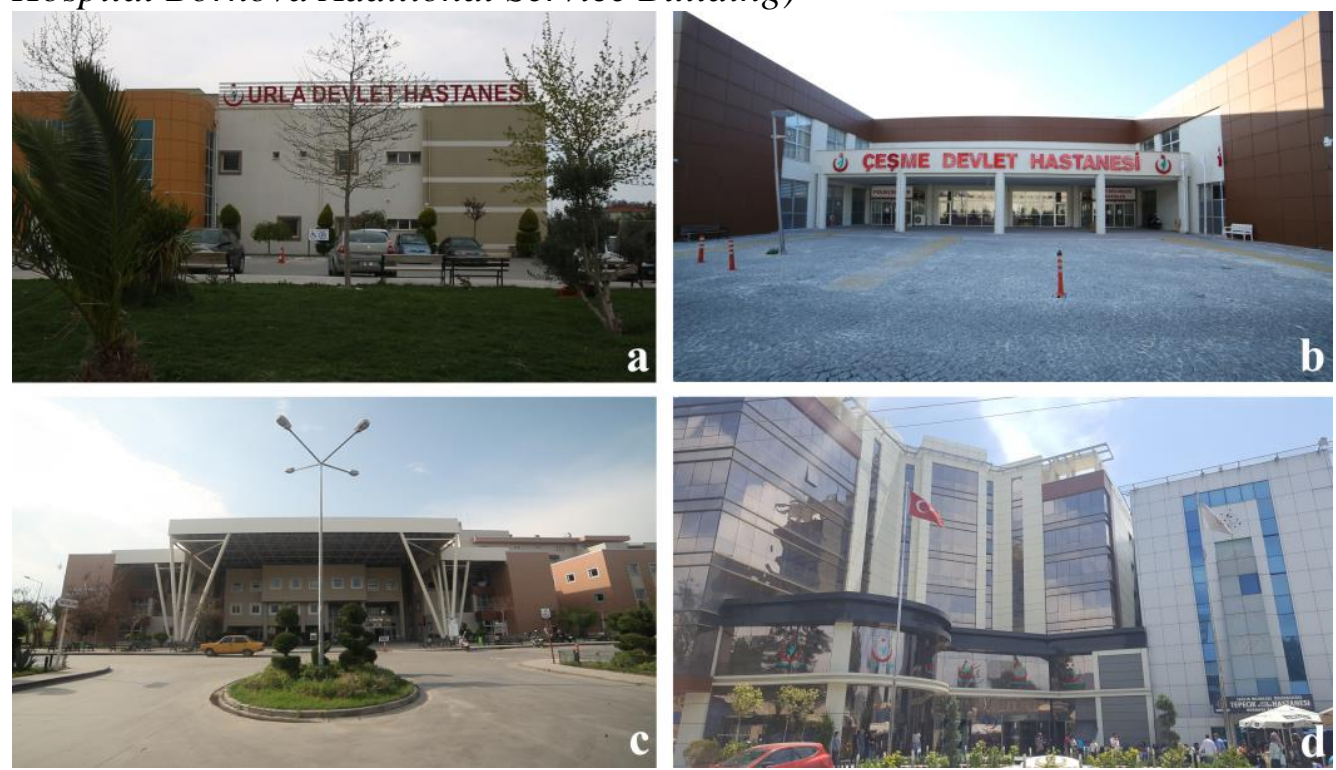

Source: HI Project Archive, 2017.

39. M. C. Poulin and A. Aia, Interior Design for Health Care (n.d.), 247-260. 
Vol. 4, No. 2 Cetin et al.: The Effects of Interior Design Parameters on the...

Figure 2. The Selected Four Hospitals, Nurse Stations

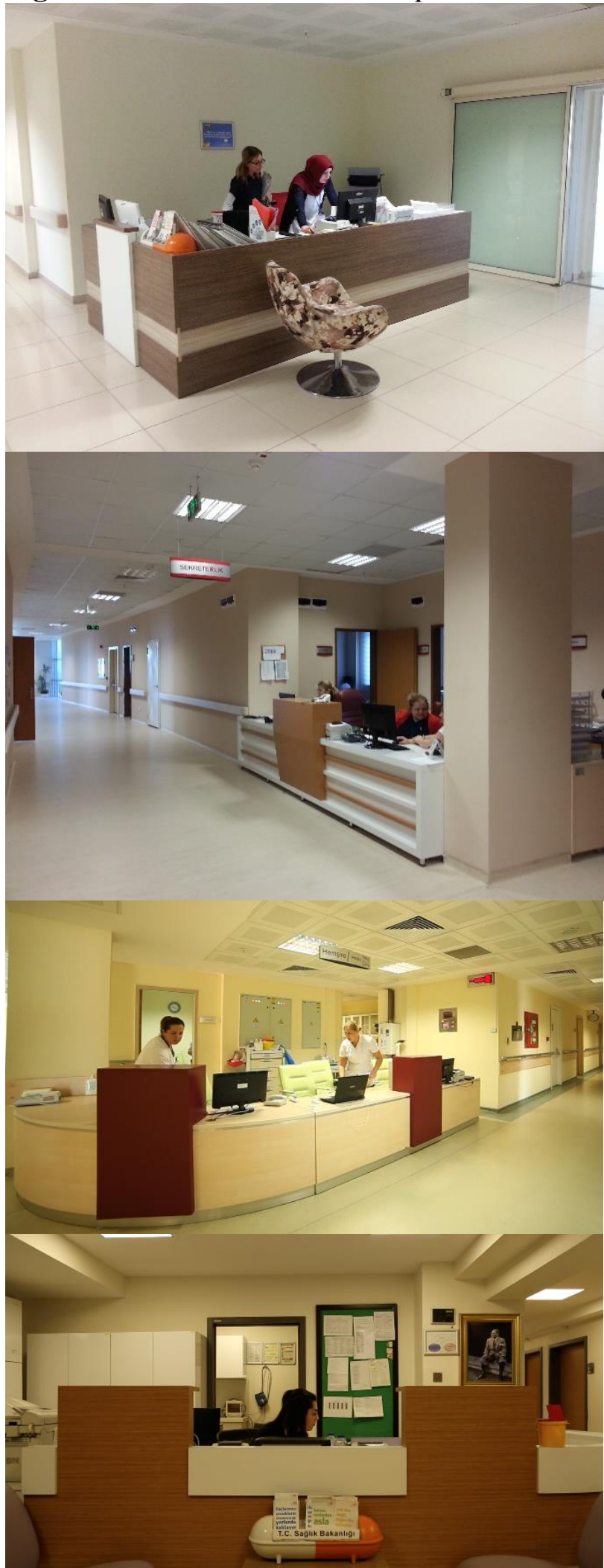

Source: HI Project archive, 2017. 
Within the scope of this research, five work packages were determined: ${ }^{40}$

1. Preliminary preparation, i.e. the collecting of data, literature review, supplying necessary equipment, and getting written permissions $\left(1^{\text {st }}\right.$ month)

2. Observations, taking photographs, shooting videos, applying questionnaires and interviews $\left(2^{\text {nd }}-4^{\text {th }}\right.$ months $)$

3. Preparing data for analysis and project deliverables $\left(4^{\text {th }}-5^{\text {th }}\right.$ months $)$.

4. Analyzing data

5. Sharing/presentation of the outcomes of data through a booklet (interior design proposals), film, blog, seminar, paper presentation and project reports $\left(7^{\text {th }}-12^{\text {th }}\right.$ months $)$

\section{Work Package-1}

A literature review related to general design principles of hospital interiors was made. Additionally, a literature review on perception issues both in hospital interiors and other spaces was investigated.

\section{Work Package-2}

After the literature review, hospital visits were made for observation, photo shooting and pre-detections. During these visits, test interviews were made with hospital directors to discover basic problems. In addition, nurse names were determined for questionnaire and interviews. Contact information of each nurse was supplied; then, peer-to-peer contact was made with them via an e-mail, which explained the aim of the project and the expectations of them, the process of questionnaires and interviews, confidentiality during the data collection, copyright forms and introducing researchers.

After observations and pre-detections, necessary permissions were supplied from İzmir South and North Public Hospitals Associations via Yaşar University. Then, semi-structured interviews and structured questionnaires were implemented. To be able to determine the number of the nurses to whom questionnaire was conducted, the total number of nurses in each hospital was specified. With the support of the statistical consultant, the number of nurses from each sample group was discovered (see Table 1):

40. In this paper, only three of them, which mainly dealt with nurse stations, are included. 
Table 1. Nurse Numbers to whom Questionnaire was Conducted and Their Distribution according to Hospitals

\begin{tabular}{|l|c|c|}
\hline \multicolumn{1}{|c|}{ Hospital Name } & Nurse Number (Total) & $\begin{array}{c}\text { Nurse Number (Sample } \\
\text { Population) }\end{array}$ \\
\hline Urla Public Hospital & 120 & 34 \\
\hline Çeşme Public Hospital & 42 & 12 \\
\hline Tire Public Hospital & 137 & 38 \\
\hline $\begin{array}{l}\text { Tepecik Training } \\
\begin{array}{l}\text { Research Hospital } \\
\text { Bornova Additional } \\
\text { Service Building }\end{array}\end{array} \quad 154$ & 43 \\
\hline
\end{tabular}

For the sampling method, "Stratified Simple Random Sampling" was used. Each hospital is organized as one for each layer. While determining the number of questionnaires to be given to nurses, the sample size is calculated one by one comparatively to the total number of nurses in the related hospital (see Figure 3).

Figure 3. Sample Size Formulation ${ }^{41}$

$$
n=\frac{N Z^{2} \cdot 25}{\left[d^{2 *}[N-1]\right]+\left[Z^{2 \star} \cdot 25\right]}
$$

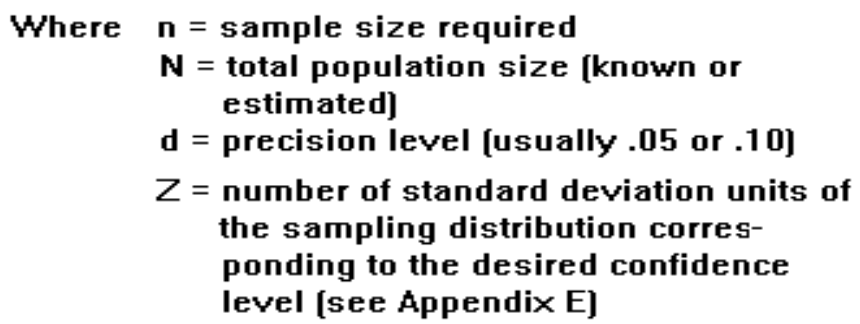

To be able to test the intelligibility and clarity of questions, a test questionnaire was conducted with one nurse from each hospital as a pilot study. Moreover, opinions of the sample population regarding the contents of questions were received from these questionnaires, which have not been evaluated. Assistant Professor Dr. Banu Özgürel, who is an academic member of the Department of Mathematics, Faculty of Science and Letters at Yaşar University, provided consultation during the phases of arranging project questionnaire questions for acquiring suitable data for SPSS program and transferring these results to SPSS program. A hybrid method was used for completing the questionnaires. In this regard, according to the first planning, we aimed to distribute questionnaires in person at two hospitals, while in the other two hospitals questionnaires were given online (by Survey Monkey). However, as the return rate of online questionnaires was less than expected, all the questionnaires were eventually distributed manually.

Questionnaires consisted of five parts, which were called pre-questionnaire, plan and furniture layout, color, light and material and the data were analyzed

41. Current $d$ (Precision level $)=0.05$. Related $Z$ value is received as 1.96 . 
through SPSS software. Questionnaire questions were structured considering the current literature related with basic components of interior architecture and the literature regarding interior design quality in healthcare buildings. ${ }^{42}$ Accordingly, questionnaire questions were formed inquiring whether the following interior design elements meet the expectations of physical requirements of nurses like usefulness, security, ergonomics, hygiene, flexibility and accessibility, as well as their psycho-social necessities like aesthetic taste, belonging, personalization, controlling desire, privacy and border themes.

1. Plan and Furniture Layout

2. Color

3. Lighting

4. Materials

To be able to allow the sample population to express themselves clearly, questionnaires included open-ended questions. For the confidentiality of the questionnaire, a privacy statement was presented to the participants with the guidance of a legal advisor.

Semi-structured interviews with nurses were realized as another component of the field survey. For this, interviews were made with two nurses from each hospital (total 8 nurses). Video shoots of all these interviews were completed by scholarship students from the Faculty of Communication. In addition to the defined questions, the participants were allowed to enlarge the answers and enrich the data, which was also suitable for the structure of the interview. The questions of the interviews, each of which took approximately 30-45 minutes, followed the questionnaire content. Some of the questions of the interview are exemplified below:

- Do the colors of the floor and walls affect your working activities? How? Is color selection suitable for the spaces?

- How does the furniture of this space affect your working activities? Can you explain by giving examples? Is the furniture suitable for your physical activities? Does the furniture provide flexibility according to different nurses?

- Is it important for you that the lighting is natural or artificial?

The coordinator and researchers visited each hospital three times as preinterview and observations in the process of work package-2, while scholar students visited each hospital two times.

42. J. Coles and N. House, The Fundamentals of Interior Architecture (Lausanne: AVA Publishing SA, 2007); S. Leydecker, Designing Interior Architecture: Concept, Typology, Material, Construction (Basel: Birkhauser Verlag AG, 2013); M. Pegler, The Fairchild Dictionary of Interior Design (New York: Fairchild Publications, 2006); Brooker and Weinthal, The Handbook of Interior Architecture and Design (London and New York: Bloomsbury Academic, 2013). 


\section{Work Package-3}

Entering the data, collected via questionnaire, to SPSS was completed by two scholar students. Results of the questionnaire were analyzed and evaluated under the guidance of a statistical advisor for the project. Furthermore, interviews were deciphered by two scholar students.

\section{Findings/Results}

The study participants consisted of 127 nurses, (115 women and 12 men), of whom, 23 were in between 18-20, 9 were in between 21-25, 19 were in between 26-30, 46 were in between 31- 40, 29 were in between 41-50, and 1 was over the age of 60.55 of the participants had worked in these hospitals for 1-4 years. The findings were revealed according to the parameters.

\section{Plan Layout}

As depicted in Table 2, the appropriateness of furniture layout in working areas is closely related with the feelings of nurses. Considering the current results, the ones who found furniture layout in their working area inappropriate state that it frequently leads to feelings of being "limited and crowded"; conversely, the ones who found furniture layout in their working area appropriate state that this layout leads to feelings of being "spacious and pure".

Table 2. Cross Table Analysis of Appropriates in Furniture Layout and Emotions Left on Nurses

\begin{tabular}{|c|c|c|c|c|c|c|c|}
\hline Emotions & & & & & & & \\
\hline Appropriateness & 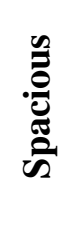 & Uై & $\frac{\check{\varpi}}{\frac{\tilde{\omega}}{d}}$ & 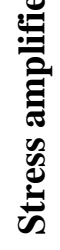 & لِّ & $\stackrel{\Xi}{\Xi}$ & 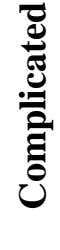 \\
\hline Strongly disagree & 6 & 7 & 2 & 10 & 11 & 2 & 9 \\
\hline Disagree & 7 & 14 & 4 & 9 & 17 & 1 & 6 \\
\hline Neutral & 5 & 3 & 3 & 1 & 5 & 4 & 3 \\
\hline Agree & 16 & 5 & 9 & 8 & 10 & 12 & 7 \\
\hline Strongly agree & 4 & 0 & 1 & 0 & 0 & 1 & 0 \\
\hline
\end{tabular}

The intensity of furniture in working areas of nurses was the other factor questioned in this study. According to the results as shown in Table 3, the nurses said that the intensity of furniture is not too much in working space, and at the same time stated that this layout leaves them with feelings of being both "spacious and limited". 
Table 3. Cross Table Analysis of Intensity in Furniture Layout and Emotions Left on Nurses

\begin{tabular}{|l|c|c|c|c|}
\hline Emotions & \multirow{2}{*}{ Spacious } & \multirow{2}{*}{ Limiter } & \multirow{2}{*}{ Pure } & \multirow{2}{*}{ Complicated } \\
\cline { 1 - 1 } Intensity of furniture & 6 & 8 & 3 & 5 \\
\hline Strongly disagree & $\mathbf{1 3}$ & $\mathbf{1 3}$ & 11 & 5 \\
\hline Disagree & 5 & 8 & 1 & 4 \\
\hline Neutral & 10 & 8 & 4 & 8 \\
\hline Agree & 4 & 6 & 1 & 4 \\
\hline Strongly agree & & & & \\
\hline
\end{tabular}

\section{Color}

In the questionnaire, two groups of adjectives were presented to participants. The first group aimed to understand the effect of color on the nurses, and the second group was to understand their feelings about these colors. The results show that color use has effects on the perception of the working environment, such as dimension (small-large, narrow-broad), hygiene (hygienic-anti-hygienic), lightness (light- dark) and order (order- messy). As shown in Table 4, the boring effect of color in a working environment creates feelings of gloom; similarly, the lighting and ordering effect of color gives a feeling of spaciousness.

Table 4. Cross Table Analysis of Effect of Color and Emotions Left on Nurses

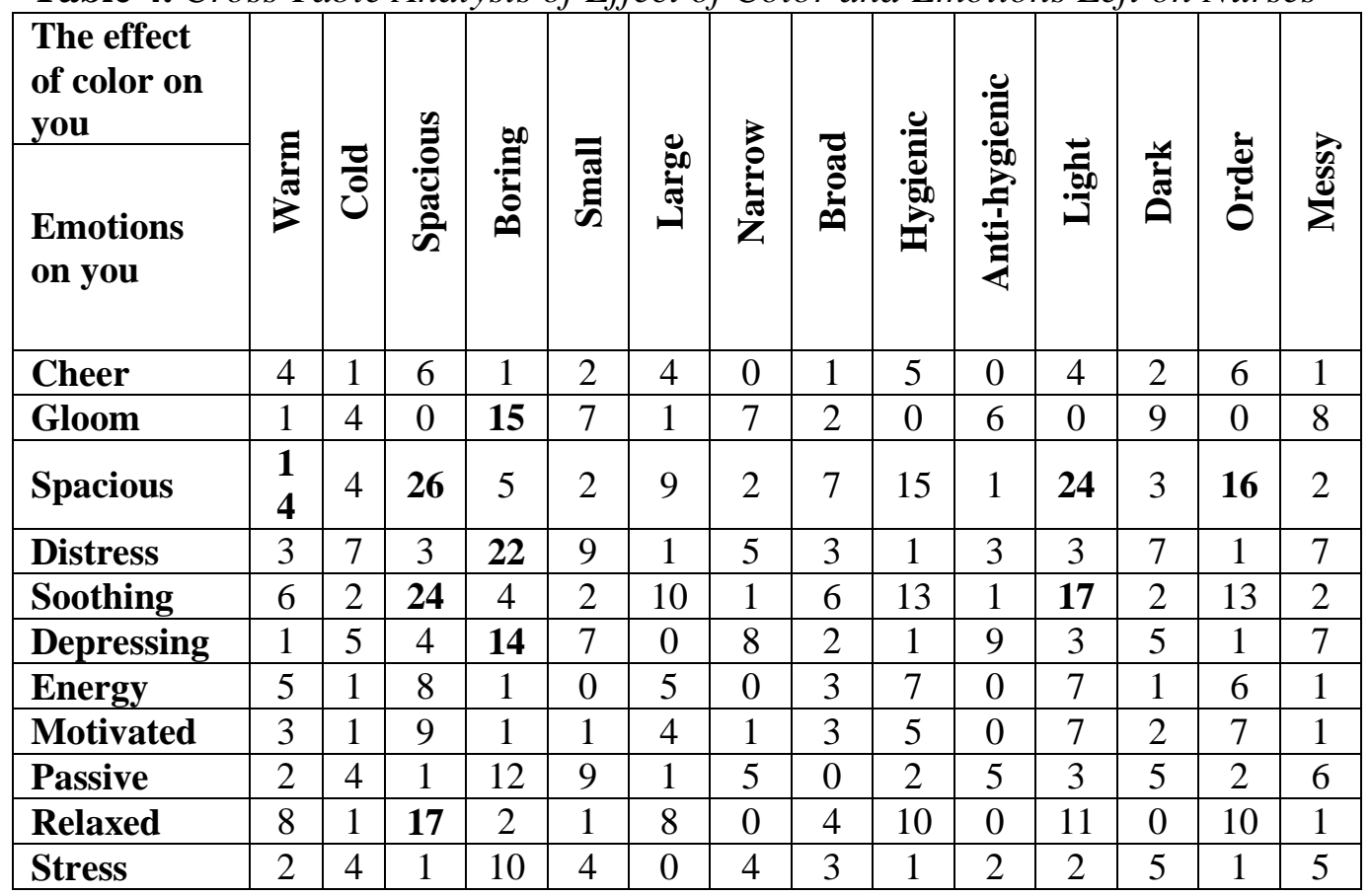

Participants were expected to select three colors they mostly prefer in their working environments. Interviewers showed a wide variety of colors from a color palette in order to determine these preferences (see Figure 4). 
Figure 4. Color Preferences of Nurses in the Work Environment

Source: HI Project archive, 2017.

Similarly, the preferences in color of furniture were also questioned. According to data, participants indicated their preferences as shown in Figure 5.

Figure 5. Color Preferences of Nurses in Furniture of their Work Environment

Source: HI Project Archive, 2017.

\section{Lighting}

The findings for the question regarding the "importance of light" demonstrated significant associations between light and nurse satisfaction. It is obvious that nurses attach importance to light in their work environment (see Table 5).

Table 5. Descriptive Analysis of Importance of Lighting on the Perception of Nurses

\begin{tabular}{|l|c|c|c|c|c|}
\hline $\begin{array}{l}\text { The } \\
\text { importance } \\
\text { of lighting }\end{array}$ & $\begin{array}{l}\text { Strongly } \\
\text { disagree }\end{array}$ & Disagree & Neutral & Agree & Strongly agree \\
\hline frequency & 4 & 6 & 11 & 52 & 54 \\
\hline percentage & 3.1 & 4.7 & 8.7 & 40.9 & 42.5 \\
\hline
\end{tabular}

The adequacy of lighting in working areas of nurses was analyzed in terms of both natural and artificial light conditions. A significant negative result in adequacy of daylight indicated that nurse stations were mostly illuminated by artificial light (see Table 6).

Table 6. Descriptive Analysis of Perception of Daylight and Artificial Light in Nurse Stations

\begin{tabular}{|l|c|c|c|c|c|}
\hline & $\begin{array}{c}\text { Strongly } \\
\text { disagree }\end{array}$ & Disagree & Neutral & Agree & $\begin{array}{c}\text { Strongly } \\
\text { agree }\end{array}$ \\
\hline Daylight & 33 & 32 & 13 & 40 & 9 \\
\hline $\begin{array}{l}\text { Artificial } \\
\text { light }\end{array}$ & 15 & 28 & 17 & 55 & 12 \\
\hline
\end{tabular}


The controlling of light was the other significant criteria in perception of light in this study. Relevantly, analyses showed that controlling daylight and artificial light is not perceived as adequate by approximately half of the participants. Furthermore, the number of participants that believed "controlling of daylight is inadequate" is higher than the number of participants that believed "controlling artificial light is inadequate" (see Table 7).

Table 7. Descriptive Analysis of Perception in Adequacy of Daylight and Artificial Light in Nurse Stations

\begin{tabular}{|l|c|c|c|c|c|}
\hline & $\begin{array}{l}\text { Strongly } \\
\text { disagree }\end{array}$ & Disagree & Neutral & Agree & $\begin{array}{c}\text { Strongly } \\
\text { agree }\end{array}$ \\
\hline $\begin{array}{l}\text { Control of } \\
\text { daylight }\end{array}$ & 24 & 36 & 16 & 39 & 12 \\
\hline $\begin{array}{l}\text { Control of } \\
\text { artificial } \\
\text { light }\end{array}$ & 14 & 36 & 21 & 42 & 14 \\
\hline
\end{tabular}

Table 8. Cross Tab Analysis of Perception in Adequacy of Artificial Light and the Importance of Light in Nurse Stations

\begin{tabular}{|c|c|c|c|c|c|}
\hline $\begin{array}{l}\text { Adequacy of } \\
\text { artificial light }\end{array}$ & & & & & \\
\hline $\begin{array}{l}\text { The } \\
\text { importance of } \\
\text { light }\end{array}$ & $\begin{array}{l}\text { Strongly } \\
\text { disagree }\end{array}$ & Disagree & Neutral & Agree & $\begin{array}{c}\text { Strongly } \\
\text { agree }\end{array}$ \\
\hline $\begin{array}{l}\text { Strongly } \\
\text { disagree }\end{array}$ & 1 & 1 & 1 & 2 & 0 \\
\hline Disagree & 2 & 4 & 0 & 0 & 0 \\
\hline Neutral & 0 & 5 & 6 & 1 & 0 \\
\hline Agree & 2 & 11 & 6 & 47 & 1 \\
\hline Strongly agree & 12 & 14 & 4 & 35 & 21 \\
\hline
\end{tabular}

The relationship between the importance of lighting and adequacy of artificial light is indicated in Table 8 . This direct proportion indicates that the participants who state lighting is important find artificial light inadequate in their working space. Conversely, this situation is changing in daylight. As seen in Table 9, there does not exist a drastic difference between the number of participants that think that lighting is strongly important but daylight is inadequate, and lighting is strongly important as well as the daylight is adequate. This result reveals that the perception of artificial light is more directly proportioned with the importance of light in nurse stations than daylight. The inadequacy of daylight conditions in nurse stations is one of the most important effects on this result. 
Table 9. Cross Tab Analysis of Perception in Adequacy of Daylight and the Importance of Light in Nurse Stations

\begin{tabular}{|l|c|c|c|c|c|}
\hline $\begin{array}{l}\text { Adequacy of daylight } \\
\text { light }\end{array}$ & $\begin{array}{l}\text { Strongly } \\
\text { disagree }\end{array}$ & Disagree & Neutral & Agree & $\begin{array}{c}\text { Strongly } \\
\text { agree }\end{array}$ \\
\hline Strongly disagree & 3 & 0 & 0 & 2 & 0 \\
\hline Disagree & 1 & 5 & 0 & 0 & 0 \\
\hline Neutral & 2 & 1 & 5 & 4 & 0 \\
\hline Agree & 11 & $\mathbf{1 8}$ & 3 & $\mathbf{3 4}$ & 1 \\
\hline Strongly agree & $\mathbf{2 9}$ & $\mathbf{1 9}$ & 10 & $\mathbf{1 7}$ & 11 \\
\hline
\end{tabular}

Materials

In accordance with the literature about physical and psychological features of material, some adjective groups were defined for evaluating floor material in nurse stations. Participants were expected to check these adjectives about their work environments according to their importance level. The findings obviously showed that the features related with "easy maintenance," such as ease of cleaning and non-slipping, are more important than the others. "Easy use," like being stain-proof and antibacterial, is more important than the "aesthetic features" (see Table 9). Relevantly, participants were asked to evaluate materials in order to their perception of space and give some contrasting adjective pairs such as warm/cold, spacious/boring, small/large, narrow/ broad, hygienic/non-hygienic, light/dark, and in order/messy. The results interpreted with the results of important features of floor materials they marked are shown in Table 10. According to the results, participants related the adjectives "shiny" with "largeness" and "broadness" with "lightness"; similarly, they related "the feature of being jointless" with "the perception of hygiene".

Table 10. Analysis of the Perception in Importance of Floor Material in Nurse Stations

\begin{tabular}{|c|c|c|c|c|c|c|c|c|}
\hline $\begin{array}{l}\text { Importance of } \\
\text { floor material }\end{array}$ & 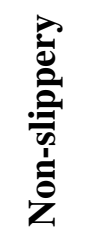 & 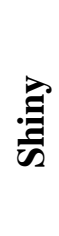 & $\overline{\bar{\Xi}}$ & 总 & 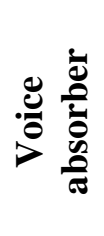 & 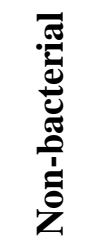 & 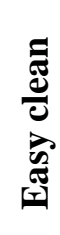 & 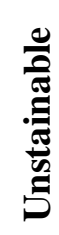 \\
\hline frequency & 96 & 28 & 39 & 34 & 48 & 78 & 99 & 66 \\
\hline percentage & 75,6 & 22 & 30,7 & 26,8 & 37,8 & 61,4 & 78 & 52 \\
\hline
\end{tabular}




\section{Discussion and Conclusions}

The theory of evidence based design and user-centered design commonly emphasize the importance of user for increasing the quality of an interior design. Although, it is obvious that the criteria of "user centered design" and "evidence based design" are valid for all user groups (patient, staff and family of patients) in healthcare facilities, this study emphasized nurses and their working stations. Accordingly, the physical and psychological needs of nurses in their working area were revealed. It can be stated that interior design elements questioned through this study - furniture layout, color, lighting and materials - have significant effects on decreasing staff stress, increasing staff effectiveness, and increasing staff satisfaction through the analysis of nurses' perceptions.

Literature evaluation and questionnaire analysis revealed that the layout of furniture not only affects the physical function, but also affects the psychology and social contact of the nurse working areas. Analysis of the relation between appropriateness in furniture layout and its effect on nurses' emotions indicated the direct and parallel link between them.

The other parameter that has an important effect on design quality is color in nurse stations. Through its effect on design quality, it impacts the psychology of nurses in terms of concentration, alertness, aggression and stress during their working hours. Likewise, the cross table analysis of the study showed that the effect of color on emotions resulted in parallel feelings of the nurses.

The use of lighting in healthcare interiors also has a crucial role on the quality of design. Therefore, its appropriate use promotes a sense of wellbeing and even impacts recovery rates, navigation, way finding, aesthetics, user friendly mediums, safety and coding in these spaces. In parallel with the literature, questionnaire analysis indicated that nurses evaluated lighting as an important interior parameter in their working environment. Additionally, control of artificial light was evaluated more positively than the control of daylight in these spaces. Also, the perception of artificial light was more directly proportioned with the importance of light in nurse stations than daylight.

Besides furniture layout, color and lighting, materials of healthcare interiors also were considered in the context of this study. Especially physical properties, such as safety, effectiveness for easy cleaning, maintenance, appropriateness for different users, etc. have an important effect on the quality of design in healthcare interiors. In addition, some of the surface features of materials have an effect on the perception of physical properties of materials as positive or negative. In accordance with literature, participants related the adjectives "shiny" with "largeness" and "broadness" with "lightness"; similarly, they related "the feature of being jointless" with "the perception of hygiene".

This study has a potential to create awareness about designing healthy, secure, motivating, supportive, and relaxing work environments that support nurses' physical and psychological health. By means of this study, a notable 
change in the attitude of designers, managers and educators is expected for the perception and creation of nurse working areas in healthcare interiors. In further studies, we aim to propose specific design solutions related to plan layout, color, material, furniture and lighting through the data collected and evaluations within this study.

\section{Acknowledgments}

We would like to thank Yaşar University for the funding of the scientific research project, of which this study is a part of. We also would like to thank Prof. Dr. Sevil Sarıyıldız for encouraging us in the realization of the project; Asst. Prof. Dr. Banu Özgürel for her tremendous help in data analysis; Prof. Dr. Meral Sungurtekin Ö̈zkan for her guidance in legal issues; Assoc. Prof. Dr. Sezin Tanriöver for her initial consultancy for the project; Zeynep Akdeniz, Elif Yurtsever for their help in data collection and interview deciphering; and Ezgi Uz, Damla Keskin and Seçkin Özturkut for their help in data collection.

\section{Bibliography}

Andrade, C. and A. S. Devlin. "Stress reduction in the hospital room: Applying Ulrich's theory of supportive design." Journal of Environmental Psychology 41 (2014): 125-134. DOI= 10.1016/j.jenvp.2014.12.001.

Andrade, C., M. L. Lima, F. Fornara and M. Bonaiuto. "Users' Views of Hospital Environmental Quality: Validation of the Perceived Hospital Environment Quality Indicators (PHEQIs).” Journal of Environmental Psychology 32, no. 2 (2012): 97-111. http://doi.org/10.1016/j.jenvp.2011.12.001.

Barış1k, P. The Relationship between Behavioral and Sensory Comfort Parameters and Spatial Organisation in Hospital Polyclinic Spaces. Master Thesis. Beykent University, 2013.

Brooker and Weinthal. The Handbook of Interior Architecture and Design. London and New York: Bloomsbury Academic, 2013.

Center for Health Design. An Introduction to Evidence Based Design for Healthcare Facilities. Concord, CA: The Center for Health Design, 2008.

Coles, J. and House, N. The Fundamentals of Interior Architecture. Lausanne: AVA Publishing SA, 2007.

Çetinkaya, Ç., A. Cılasun and B. Hancı Geçit. "Evaluation of indoor environmental control and psychology in healthcare: a case study on inpatient rooms in hospitals." In Proceedings of the SBE Symposium (Istanbul, 2016), 474-482. DOI=http://www.sbeistanbul.com/assets/SBE16_Papers_ing-24-10-2016.pdf.

Dalke, H., J. Little, E. Niemann, N. Camgoz, G. Steadman, S. Hill and L. Stott. "Colour and lighting in hospital design." Optics and Laser Technology 38, no. 4 (2006): 343-365.

Demarco, A. and N. Clarke. "An interview with Alison Demarco and Nichol Clarke: Light and colour therapy explained." Complementary Therapies in Nursing and Midwifery 7 (2001): 95-103. 
Dikmen, O. Children's Hospital Schools as Social Environments and Their Effects on Healing and Well-Being: Case Study in Izmir Behçet Uz Children's Hospital School. Master Thesis. Izmir University of Economics, 2012.

Evans, G. W. and J. M. McCoy. "When buildings don't work: The role of architecture in human health." Journal of Environmental Psychology 18, no. 1 (1998): 85-94. DOI= http://dx.doi.org/10.1006/jevp.1998.0089.

Erdemli, E., I Esen, S. Hilal, K. Jakshybekov, Z. Öktem, I. Özmen, B. Şengül, A. Turgay, C. Tünger and B. Zeka. Design Guidelines for Nonclinical Areas in Hospitals: Case of Güven Hospital. Graduate Student Work. Bilkent University, 2013. http://bit.ly/2gudrHB.

Gifford, R. "Environmental psychology and sustainable development: Expansion, maturation, and challenges." Journal of Social Issues 63 (2007): 199-212.

Göler, S. Style, Color, Material, Texture and Light Effects on the Location of Perception. Master Thesis. Mimar Sinan Fine Art University, 2009.

Haliloğlu Kahraman, E. "Using user-centered design approach in course design." Procedia Social and Behavioral Sciences 2 (2010): 2071-2076.

İğdir, S. F. Evaluation of Design Studios in Terms of Environmental Comfort Conditions. Master Thesis. Bilkent University, 1998.

Jakub, B. "Evidence based design for contemporary healthcare facilities." Space and Form 29 (2014). DOI: 10.21005/pif.2017.29.A-02.

Karakurt, A. S. Critical Analysis and Evaluation of Hospital Main Entrances According to Design and Performance Criteria in the Case of Turkey. Master Thesis. Middle East Technical University, 2003.

Leydecker, S. Designing Interior Architecture: Concept, Typology, Material, Construction. Basel: Birkhauser Verlag AG, 2013.

Malkin, J. Hospital Interior Architecture: Creating Healing Environment for Special Patient Populations. New York: Van Nostrand Reinhold, 1992.

McCullough, C. Evidence-Based Design for Healthcare Facilities. USA: Sigma Theta Tau, 2009.

Morelli, A. Implications of Nursing Station Design on Nurses' Psychosocial Health and Work Behavior. Master Thesis. Environmental Psychology D, 2007.

Pegler, M. The Fairchild Dictionary of Interior Design. New York: Fairchild Publications, 2006.

Potter, P., L. Wolf, S. Boxerman, D. Grayson, J. Sledge, C. Dunagan and B. Evanoff. "Understanding the cognitive work of nursing in the acute care environment." Journal of Nursing Administration 35, no. 7-8 (2005): 327-335.

Poulin, M. C. and A. Aia, A. Interior Design for Health Care (n.d.), 247-260.

Ruck, N. C. Building Design and Human Performance. New York: Van Nostrand Reinhold, 1989.

Ruga, W. Designing for the six senses. Journal of Health Care Interior Design 1 (1989): 29-34.

Sadler, B. L., J. Du Bose and C. Zimring. "The business case for building better hospitals through evidence-based design." Health Environments Research and Design 1, no. 3 (2008): 22-39.

Sharpe, D. T. The Psychology of Color and Design. Chicago: Nelson-Hall Co, 1974. Sylvania, O. Lighting Options by Space or Area: Nursing Stations. 2012.

Tanriöver, S. "The healing \& supportive role of design in healthcare environments: Evidence Based Healthcare Design." Presentation within the course of "INAR 371 perception in interiors" seminar entitled Healing Role of Space on the Design of Healthcare Buildings. Yaşar University, 2016. 
Tavakkoli, S., M. M. Asaadi, A. H. Pakpour and M. Hajiaghababaei. "Environmental psychology effects on mental health job satisfaction and personal well being of nurses." Iranian Journal of Psychiatry 10, no. 3 (2015): 158-164.

Ulrich, R. S. "Effects of interior design on wellness: Theory and recent scientific research." Journal of Health Care Interior Design 3 (1991): 97-109.

Ulrich, R., C. Zimring, A. Joseph, X. Quan and R. Choudhary. The role of the physical environment in the hospital of the 21st century: a once-in-a lifetime opportunity. Concord, CA: Center for Health Design, 2004.

Wu, A. W. "Medical error: The second victim." British Medical Journal 320 (2000): 726-727. DOI= 10.1136/bmj.320.7237.726.

Zadeh, R. S., M. M. Shepley and L. T. Waggener. "Rethinking efficiency in acute care nursing units: analyzing nursing unit layouts for improved spatial." $H E R D$ Health Environments Research \& Design Journal 6, no. 1 (2012): 39-65. 